\title{
CIÊNCIANATURA
}

\section{Mercury tolerance of Penicillium sp isolated from kefir grains}

Antonio F. de Oliveira ${ }^{1,2^{*}}$, Iracilema Sena Silva ${ }^{1}$; Adriana M. Ferreira ${ }^{3}$, Josué A. Velázquez-Moyado ${ }^{3}$, Roberto Messias Bezerra ${ }^{2}$, José Carlos T. Carvalho ${ }^{3}$, Irlon M. Ferreira ${ }^{4}$, Alexandro Cezar Florentino ${ }^{2}$.

${ }^{1}$ Pós-doutorando, Bolsista do PNDP/CAPES. Programa de Pós-Graduação/Mestrado em Desenvolvimento Regional da

Universidade Federal do Amapá . Macapá, Amapá, Brazil

${ }^{2}$ Laboratório de Absorção Atômica e Bioprospecção, Departamento de Pós-Graduação, Universidade Federal do Amapá, Macapá, Amapá, Brazil

${ }^{3}$ Laboratório de Pesquisa em Fármacos, Curso de Farmácia, Departamento de Ciências Biológicas e da Saúde, Universidade Federal do Amapá, Macapá, Amapá, Brazil

${ }^{4}$ Laboratório de Biocatálise, Departamento de Ciências Biológicas e da Saúde, Universidade Federal do Amapá, Macapá,

Amapá, Brazil

\begin{abstract}
Inorganic contaminants contaminations poses one of the greatest threats to the environment and human health. It has been recently reported that probiotics protect the organism from inorganic contaminant damage by their bioabsorption capacity of its components. Kefir is a beverage obtained through the metabolized fermentation by Lactobacillus and yeasts in the forms of aggregate, creating the grains of kefir. In addition to hundreds of species of bacteria these grains also contain filamentous fungi living in symbiosis. In order to isolate inorganic contaminant resistant microorganism, the kefir grains were crushed and the supernatant obtained was inoculated in malt-agar medium (2\%) and cultured for 120 hours. Occurred formation of halos of growth which were measured every 24 hours, in this way the growth inhibition was determined. The isolated microorganism was also cultured in liquid media for five days. The taxonomic analysis revealed to be, fungus of the genus Penicillium. The results obtained showed the capability of mercury bioabsorption by the colonies of Penicillium sp isolated from kefir. Modifying the conditions of the media ( $\mathrm{pH} 4.0$ and 9.0) the bioabsorption did not drastically modify the activity. Contrary to what was expected there was an increase in biomass when growth in liquid medium, which could suggest the formation of storage structures for the inorganic contaminants around the cell membrane. These results suggest that kefir contains in its composition microorganisms with potential to protect people who consume it from harmful damages caused by inorganic contaminants.
\end{abstract}

Keywords: Kefir grains; Bioabsorption; Inorganic contaminants; Probiotics 


\section{Introduction}

Inorganic contaminants contaminations are one of the greatest threats to the environment and human health because of their toxicity aggravated by the fact that they contain non-biodegradable properties, which means they are bioaccumulated in the organism and soils (SHENG et al., 2016). Through the effect of biomagnification on the food chain, inorganic contaminants can threaten the health of humans (ZHAI et al., 2016).

In order to alleviate the effects of Inorganic contaminant toxicity, several methods for removal have been suggested. Among these are the use of algae and microorganisms (JAHROMI et al., 2017). The use of probiotics to remove Inorganic contaminants from the organism, is also well known (TONG et al., 2017; ZHAI et al., 2017). It has been reported that some bacteria from probiotics possess great potential to eliminate Inorganic contaminants from food and water (ELSANHOTY et al., 2016). For example, Lactobacillus plantantarum, a natural inhabitant of the intestine promotes several beneficial effects to health, among there is the Inorganic contaminant removal (ABU-BRAKA et al., 2017). Previously studies have been corroborated the bioabsorption and elimination of lead by the lactic acid bacteria L. pentosus and L. acidipiscis (JAHROMI et al. 2017).

Intestinal lumen contains millions of cells that are expelled and renewed every day. ZHAI et al. (2016) confirmed that a diet supplemented with probiotics might exert a protective effect against Inorganic contaminants ingested because when the digestive process expelled these microorganisms also eliminates the bio-absorbed inorganic contaminants.

The ability of probiotics to remove inorganic contaminants from the human body has been confirmed (THONG et al., 2017; ZHAI et al., 2017). For example, Lactobacillus plantarum, a component of probiotics and also a natural inhabitant of the intestine, promotes several beneficial health effects, including the removal of Inorganic contaminants (ABU-BRAKA et al., 2017).

Zhai et al. (2016) confirmed that a diet supplemented with probiotics might exert a protective effect against inorganic contaminant ingested. Elsanhoty et al. (2016) confirmed the ability of lactic acid bacteria and probiotic bacteria to remove Inorganic contaminants including cadmium $(\mathrm{Cd})$, lead $(\mathrm{Pb})$ and arsenic $(\mathrm{As})$ as well as aflatoxin B1 (AFB1) from contaminated water, reducing the tolerance limit approved by World Organization of Health (WHO).

Kefir is a beverage obtained from the fermentation of milk, fruit juice or sugar being metabolized by Lactobacillus and yeast that together constitutes the "kefir grains". The kefir grains are similar to cabbage blossom, sizing from $3 \mathrm{~mm}$ to $1 \mathrm{~cm}$. They have irregular shape, white or yellow color, actually they assume the color of the media in which they grown (OLIVEIRA et al., 2017a) and contains firm texture (LA RIVIERE et al., 1967) known as "kefir grains". Kefir is considered a probiotic composed basically of lactic acid bacteria and yeast. Other microorganisms eventually enter in their composition such as filamentous fungi and bacteria. Kefir is characterized by the presence of fungi with high biosynthetic capability (OLIVEIRA et al., 2017b).

What makes it interesting to use kefir grains to assess their capability for bioabsorption and the synergy between the microorganisms involved. Thus, in the present we study we isolate a microorganism of kefir responsible for the bioabsorption of inorganic contaminant, suggesting that the ingestion of it, can confer to the organism protection against damages caused by Inorganic contaminant ingestion.

\section{Material and Methods}

\subsection{Isolation of Penicillium sp of kefir grains}

$10 \mathrm{~g}$ of kefir grains diluted in $10 \mathrm{ml}$ of distilled water were crushed in a homogenizer ultra-turrax. A droplet of the obtained supernatant was inoculated into Petri dishes in which malt-agar medium (2\%) previously poured. As a result, fungal colonies were formed with morphological structures (conidiophores and conidia) that were evaluated for identification at gender level, based on sections of the morphological characteristics. The resulting microorganism was identified as Penicillium sp.

\subsection{Preparation of the culture medium}

Culture medium for fungus was prepared using malt-agar medium (2\%) at pH 7.0. In Petri dishes (90 mm), approximately $25 \mathrm{ml}$ of culture medium was poured. In this medium isolate microorganism was inoculated with inoculation loop

\subsection{Toxicological Prediction}

In order to identify some undesirable properties of the compounds with mercury the server http://tox.charite.de/tox/ was used. The criteria used was similarity of the functional groups in the molecule, as well with the toxicological properties such as; toxicological class, toxic fragments generation and LC50. 


\subsection{Cultivation of Penicillium sp in solid medium and Minimum Inhibitory Concentration (MIC)}

To analyze the radial growth, Penicillium sp was inoculated in malt-agar medium ( $2 \%$ ) incubated for $72 \mathrm{~h}$ at room temperature $\left(27 \pm 1^{\circ} \mathrm{C}\right)$ in Petri dish $(90 \mathrm{~mm})$ supplemented with different concentrations of the $\operatorname{Hg}\left(\mathrm{NO}_{3}\right)_{2}(0,100,150,175$ and $200 \mathrm{ppm})$.

Thereafter, the growth halo was measured using a digital caliper. Inhibition of growth was calculated using the following formula:

Where MIC is the Minimum Inhibitory Concentration, $\mathrm{X}$ is the mean of radial growth of the control without the inorganic contaminant $\left(\mathrm{Hg}\left(\mathrm{NO}_{3}\right)_{2} 0.0 \mathrm{ppm}\right)$ and $\mathrm{Y}$ is the mean of radial growth obtained by culturing the fungus in medium with inorganic contaminant.

The Minimum Inhibitory Concentration (MIC) of the metal caused 50\% of growth inhibition $\left(\mathrm{MIC}_{50}\right)$ for the selected microorganism Penicillium sp.

Growth was measured using the halo method using a digital caliper Digimess (Brazil). The first 24 hours were left free of measurement to enabling the growth of the fungus, and then the growth measures were checked every 24 hours until reaches the maximum growth in the disk of the $90 \mathrm{~mm}, 120$ hours later.

The control was characterized as containing inorganic contaminant free culture medium. Meanwhile mercury was inserted into the culture medium at the concentrations of 100, 150, 175 and $200 \mathrm{mg} / \mathrm{L}$ of mercury nitrate $\mathrm{Hg}\left(\mathrm{NO}_{3}\right)_{2}$. $\mathrm{After}$ a period of 120 hours the halo of the isolate growing in the medium with different concentrations of mercury nitrate $(0,100,150,175$ and $200 \mathrm{ppm}$ ) was measured and calculated.

\subsection{Penicillium sp biomass and Minimum Inhibitory Concentration (MIC)}

To obtain the total biomass, Penicillium sp as inoculated in malt-agar medium (2\%) after that incubated at room temperature $\left(27 \pm 1^{\circ} \mathrm{C}\right)$ using shaker with at $75 \mathrm{rpm}$ of mixing speed. Small portions $(0.5 \mathrm{~mm})$ of the fungus was transferred to an Erlenmeyer flask $(250 \mathrm{ml})$ containing $100 \mathrm{ml}$ of the malt-agar medium $(2 \%)$ supplemented with $\mathrm{Hg}\left(\mathrm{NO}_{3}\right)_{2}$ at different concentrations of $(0$, $100,150,175$ and $200 \mathrm{ppm}$ ) and incubated at $27 \pm 1^{\circ} \mathrm{C}$ for $72 \mathrm{~h}$. After this period the culture medium with biomass was filtered on whatman $n^{\circ} 1$ filter paper and washed with deionized water in order to remove the excess of culture media.

\subsection{Analysis by Scanning Electron Microscopy}

The mycelium of Penicillium sp was scrutinized by Scanning Electron Microscopy (SEM) (TM3030Plus, Hitachi, Japan). The acceleration voltage used was set at $15 \mathrm{kV}$. The magnification used was x $25 \mathrm{~K}$. It was attempted to analyze the morphological changes made by the mercury exposition.

\subsection{Statistical Analysis}

Experiments were conducted with three replicates considering the isolates as factor A and metal concentration as factor B. The analysis of variance (one-way ANOVA) followed by a Tukey test was conducted using software R 3.4.3 (R Core Team, 2017). Differences were considered significant when $\mathrm{p} \leq 0.05$.

\section{Results}

\subsection{Effects of mercury on the growth of Penicillium $s p$}

Table 1 shows the effects of the different concentrations of mercury on the mycelia growth of Penicillium sp isolated from kefir grains. When the concentration of $175 \mathrm{mg} / \mathrm{L}$ was used, inhibition (MIC) was only $17 \%(70.0 \pm 1.04 \mathrm{~mm})$.

The analyzes indicated that the concentrations were different $(\mathrm{F}=36.6, \mathrm{p}<0.05)$. Only on the concentration of $200 \mathrm{mg} / \mathrm{L}$ of mercury, total inhibited of the growth of the microorganism occur. Therefore, the data demonstrate that the microorganism has a high capacity of tolerance in the absorption of mercury 
Table 1. Growth of Penicillium sp isolated from kefir grain in malt agar medium $2 \%$ with different concentrations of mercury

\begin{tabular}{|c|c|c|c|c|c|c|c|c|}
\hline \multirow[b]{2}{*}{ Strain } & \multirow{2}{*}{$\begin{array}{c}0,0 \mathrm{mg} / \mathrm{L} \\
\mathrm{D} \\
\mathrm{mm}\end{array}$} & \multicolumn{2}{|c|}{$100,0 \mathrm{mg} / \mathrm{L}^{\mathrm{ns}}$} & \multicolumn{2}{|c|}{$150,0 \mathrm{mg} / \mathrm{L}^{*}$} & \multicolumn{2}{|c|}{$175,0 \mathrm{mg} / \mathrm{L}^{* * *}$} & \multirow{2}{*}{$\frac{\text { ANOVA }}{\mathbf{F}}$} \\
\hline & & $\begin{array}{c}\text { D } \\
\text { mm }\end{array}$ & $\%$ IC & $\begin{array}{c}D \\
\mathrm{~mm}\end{array}$ & $\%$ IC & $\begin{array}{c}\text { D } \\
\mathrm{mm}\end{array}$ & $\%$ IC & \\
\hline GK -1 & 90 & $\begin{array}{c}87 \\
\pm 0,86\end{array}$ & 3 & $\begin{array}{c}78 \\
\pm 0.29\end{array}$ & 13 & $\begin{array}{c}70 \\
\pm 1.04\end{array}$ & 17 & $36,6^{* *}$ \\
\hline
\end{tabular}

$\mathrm{D}(\mathrm{mm})=$ Diameter in millimeters; \% IC = Inhibitory Concentrations Percent; $\mathrm{ns}=$ there was no significance in

Table 2 shows the effect of low $\mathrm{pH}$ on the growth of Penicillium sp. It can be seen that the combination of factors such as $\mathrm{pH}$ and presence of inorganic contaminant caused impact on the growth of the microorganism with inhibition of $19 \%$ in relation to the control.

Interestingly. But, maturation of the fungus was observed same under inhospitable conditions.

Table 2 - Growth of Penicillium sp isolated from kefir grains grown on malt-agar medium (2\%) with $175 \mathrm{mg} / \mathrm{L} \mathrm{mercury}$ nitrate $\mathrm{Hg}\left(\mathrm{NO}_{3}\right)_{2}$ at $\mathrm{pH} 4.0$

\begin{tabular}{|c|c|c|c|c|c|c|c|c|c|c|c|c|c|c|}
\hline $\begin{array}{l}\text { Time } \\
\text { (hs) }\end{array}$ & $\begin{array}{c}24 \\
\mathrm{~mm}\end{array}$ & $\begin{array}{c}36 \\
\mathrm{~mm}\end{array}$ & $\%$ IC & $\begin{array}{c}48 \\
\mathrm{~mm}\end{array}$ & $\begin{array}{l}\% \\
\text { IC }\end{array}$ & $\begin{array}{c}60 \\
\mathrm{~mm}\end{array}$ & $\begin{array}{l}\% \\
\text { IC }\end{array}$ & $72 \mathrm{~mm}$ & $\%$ IC & $96 \mathrm{~mm}$ & $\%$ IC & $120 \mathrm{~mm}$ & $\%$ IC & $\mathrm{F}$ \\
\hline Ctr & 0 & $\begin{array}{l}8,67 \\
\pm 0,29\end{array}$ & & $\begin{array}{c}22 \\
\pm 0,50\end{array}$ & & $\begin{array}{r}23,50 \\
\pm 0,50\end{array}$ & & $\begin{array}{l}34,17 \\
\pm 1,26\end{array}$ & & $\begin{array}{l}51,00 \\
\pm 0,50\end{array}$ & & $\begin{array}{l}62,17 \\
\pm 1,26\end{array}$ & & $984,5 * *$ \\
\hline $\begin{array}{l}\mathrm{Hg} 175 \\
\mathrm{mg} / \mathrm{L}\end{array}$ & 0 & $\begin{array}{c}3,67 \pm \\
0,29\end{array}$ & 58 & $\begin{array}{l}12.33 \\
\pm 0,76\end{array}$ & 44 & $\begin{array}{r}14,83 \\
\pm 0,29\end{array}$ & 37 & $\begin{array}{l}27,67 \\
\pm 1,04\end{array}$ & 19 & $\begin{array}{r}35,83 \\
\pm 0,58\end{array}$ & 30 & $\begin{array}{l}50,50 \\
\pm 0,50\end{array}$ & 17 & \\
\hline
\end{tabular}

$\%$ IC = Inhibitory Concentrations Percent; ${ }^{*}=p>0,05^{* *}=p>0,05^{* * *}=p>0,001$

Figure 1: Growth of Penicillium sp isolated from the kefir grain cultured in malt agar medium (2\%), showing A) control and $\mathrm{B}$ ) medium malt-agar with $175 \mathrm{mg} / \mathrm{L} \mathrm{Hg}\left(\mathrm{NO}_{3}\right)_{2}$

A)

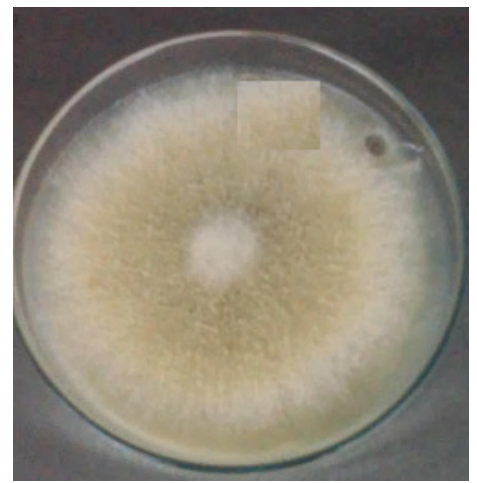

B)

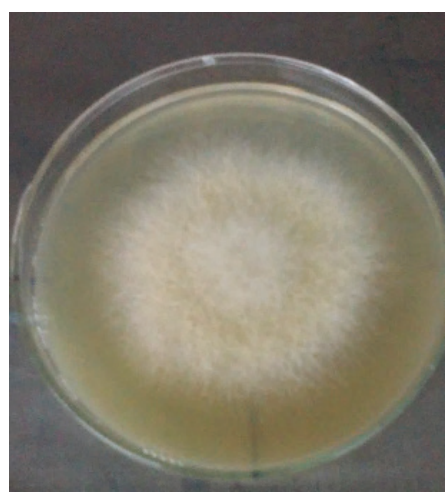

\subsection{Toxicological prediction}

In order to compare the tolerance capability of the microorganism to the inorganic contaminant with the mammals, the toxicological prediction was carried out (Table 3 ). It is noted that the lethal concentration $\left(\mathrm{LC}_{50}\right.$ ) of mercury nitrate $\mathrm{Hg}\left(\mathrm{NO}_{3}\right)_{2}$ for mammals is $25 \mathrm{mg} /$ $\mathrm{kg}$. It's considered as toxicological class 2 and this compound is not carcinogenic, but is toxic both ingested as in contact with the skin. 
Table 3 - Toxicological prediction of mercury nitrate $\mathrm{Hg}\left(\mathrm{NO}_{3}\right)_{2}$

\begin{tabular}{l|c}
\hline Toxicological Class & 2 \\
\hline $\mathrm{CL}_{50}$ & $25 \mathrm{mg} / \mathrm{kg}$ \\
\hline Molecular weight & 324,6 \\
\hline Number of Hydrogen Acceptors & 6 \\
\hline Number of atoms & 9 \\
\hline Number of connections & 6 \\
\hline Polar Molecular Surface (MPSA) & 137,76 \\
\hline
\end{tabular}

Using the toxicity predictor used was http://tox.charite.de/tox/. We calculated the Polar Molecular Surface (MPSA) for the $\mathrm{Hg}\left(\mathrm{NO}_{3}\right)_{2}$. The MPSA is a very useful parameter for the prediction of drug transport; it represents the sum of the bridges formed by the polarity of surface atoms, which it's related to the intestinal absorption capacity as well as the capability to penetrate the blood brain barrier.

\subsection{Culture of Penicillium sp in liquid medium}

Correlating the physical characteristics of Penicillium sp grown in liquid medium, it can be observed increase of the amount of biomass and also $\mathrm{pH}$, in the presence of $\mathrm{Hg}\left(\mathrm{NO}_{3}\right)_{2}(175 \mathrm{mg} / \mathrm{L})$ suggesting the presence of the metal increases the grown rate of the fungus (Table 4).

Table 4 - Biomass grown of Penicillium sp in liquid media with $150 \mathrm{mg} / \mathrm{L}$ of $\mathrm{Hg}\left(\mathrm{NO}_{3}\right)_{2}$.

\begin{tabular}{c|c|c|c}
\hline Treatment & & Biomass & $\mathrm{pH}$ \\
\hline 1 & GK-CTR & $642 \pm 9,54$ & 4,54 \\
\hline 2 & $\begin{array}{l}\text { GK } \\
\mathrm{Hg}\end{array}$ & $958,33 \pm 7,51$ & 5,95 \\
\hline
\end{tabular}

GK-CTR =control e GK-Hg= media with $\mathrm{Hg}\left(\mathrm{NO}_{3}\right)_{2}$

\subsection{Analysis of sporulation of Penicillium sp isolated from kefir grains by Scanning Electron Microscopy (SEM)}

The effects by increasing the concentration of mercury in the culture medium on Penicillium sp were perceptible on the sporulation of the fungus, decreasing the thick an the number of hyphae's per field (Figure 2B and 2C) rather than the observed on the mercury-free culture medium (Figure 2A).

Figure 2 - Scanning electron microscopy (SEM) image shows the sporulation difference in Penicillium sp cultivated in A) medium without mercury, B) with $100 \mathrm{mg} / \mathrm{L}$; C) with $200 \mathrm{mg} / \mathrm{L} \mathrm{Hg}\left(\mathrm{NO}_{3}\right)_{2}$

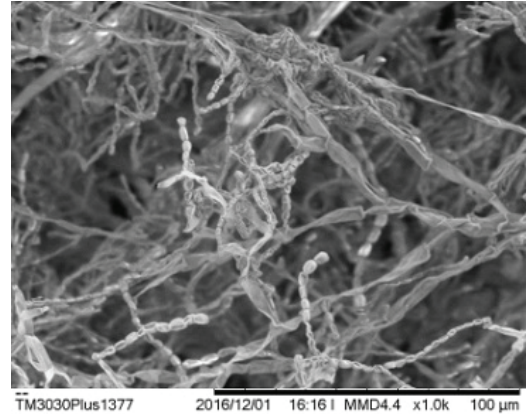

A)

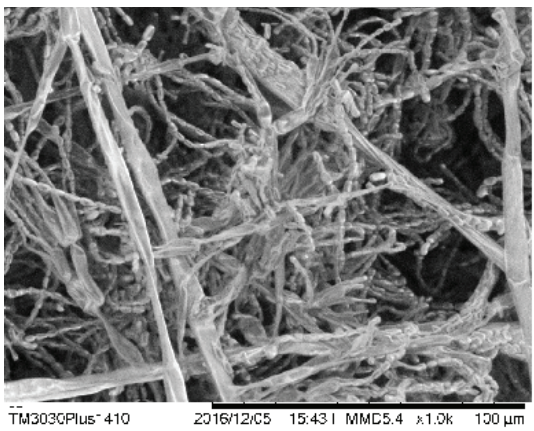

B)

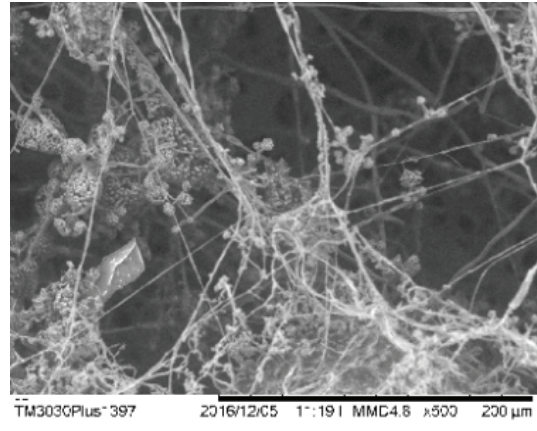

C) 


\section{Discussion}

In the present study, it has been observed that the growth of Penicillium sp was influenced by the presence of mercury in the medium (Table 1). The lethal dose $\left(\mathrm{LD}_{50}\right)$ of mercury intake for a mammal is $25 \mathrm{mg} / \mathrm{L}$. It was found in this study that the fungus resists up to $175 \mathrm{mg}$ / L of mercury nitrate, that is, seven times as much as human can tolerate.

There is evidence of the correlation between the amount of microorganisms and the amount of metals in liquid media. The high initial amount of the microorganism provides an increase in forces to overcome any metal ion transfer resistance, besides to increase in the probability of collision between the ions of the metal and the cell wall of the bioabsorbent (TANWAAR et al., 2012, EL-GENDY et al, 2017). Also, there is evidence that several microorganisms develop a tolerance due to increase of metal concentration that results on the modification of their bioabsorb capability (TANWAAR et al., 2012, EL-GENDY et al, 2017). Therefore, there is a correlation between the biomass concentration and the absorbed metal.

In this experiment, this effect is seen along with the growth of the microorganism, allowing the gradual adaptation to the contaminated environment. It was observed gradual adaptation to heavy metal with increase of the capability to survive in a contaminated environment (Table 2). These same conclusions were obtained when Penicillium (IANIS et al, 2006) and Trichoderma (CHEW et al., 2012) were cultivated in similar conditions.

The higher the dose of adsorbent in the solution, the greater the availability of exchangeable sites for the ions.

The increase of the mycelial mass does not allow the effective contact between the adsorbent and the metal. Only a partial cell aggregation occurs with high concentration of biomass leading to the decrease of active sites (EL-GENDY et al, 2017).

There is evidence showing that an increase in $\mathrm{pH}$ causes a decrease in the number of protons in solution affecting the possibility of interactions with the proteins of the cellular membrane (EL-GENDY et al, 2017). Therefore, in some cases the increase in $\mathrm{pH}$ enables bioabsorption.

Studies have shown that maximum absorption by Aspergillus versicolor, Rhizopus oligosporus, Penicillium purpurogenum, was achieved at pH 6.0 (MARTÍNEZ-JUÁREZ et al.). The maximum value of ions removal of the metal by the fungus Penicillium resedanum, Aspergillus wentii, Alternaria alternata, and Eupenicillium katangense was reached in the $\mathrm{pH}$ range of 5-8.

In this experiment, the initial $\mathrm{pH}$ of the culture medium was 7.0, which decreased after the 5 day culture to 4.6. However, when cultured in liquid medium, the $\mathrm{pH}$ of the culture medium was 7.7, so an increase in $\mathrm{pH}$ was observed

The effects of the toxicity of different concentrations of mercury on the mycelial growth of Penicillium sp isolated from kefir grain allowed to observe that as the concentration of mercury increases there is slight decrease of the growth of the microorganism. There was also difference in sporulation that was less crowded and more dispersed in relation to the control (see Figure 1). Therefore, Penicillium sp growth was influenced by doses of mercury up to $175 \mathrm{mg} / \mathrm{L}$, which shows that the microorganism has the capacity to survive in environments loaded with mercury. However, the most notable effect of mercury was on the sporulation that was delayed in relation to the control (Figure 1)

When mercury was used at a concentration of $200 \mathrm{mg} / \mathrm{L}$, almost total inhibition of fungus growth occurred and the spores became more dispersed (Figure 2C). As well, the behavior of Penicillium sp isolated from kefir grain in liquid medium showed that tolerance to mercury was higher in liquid medium than in solid medium.

Regarding the $\mathrm{pH}$ in liquid medium for the control was 4.54 while the $\mathrm{pH}$ of the medium with mercury was 5.95 which shows that the strategy of the microorganism perceptibly resulted in increased $\mathrm{pH}$. This strategy of the microorganism allowing tolerance in the environment results in increased $\mathrm{pH}$

When mercury is inserted in solid malt agar medium, a decrease in $\mathrm{pH}$ occurs, but in liquid media an increase in $\mathrm{pH}$ occurs, suggesting a defense mechanism of the microorganism whose biochemical reactions have not yet been fully delineated. It is known that the fungus grows in a relatively extensive $\mathrm{pH}$ range and adapts to extracellular $\mathrm{pH}$ through a genetic regulatory system mediated by a key PacC component, which is the $\mathrm{pH}$ transcription gene (RASPANTI et al., 2009).

As shown in Figure 2 in photos obtained by scanning electron microscopy (MEV), there is a change in the medium with mercury. Sporulation is detected in the medium with and without mercury but appears smaller in the medium with mercury. This is in agreement with the study by Raspanti et al. (2009) that concluded that mercury in this way affects sporulation in the concentration used. The physicochemical properties of the environment influence the toxicity of the contaminant to the biota (BAGY et al., 1991). The toxicity of a pollutant can be reduced in some ecosystem, while the same dose in another environment with different physico-chemical characteristics may have increased potential (BABICH, STOTZKY 1980), making this environment subject to high risk condition (BABICH, STOTZKY 1980). (BABICH, STOTZKY 1980). These latter environments should be considered high risk environments (BABICH et al 1981).

\section{Conclusion}

The results showed the capacity of mercury bioabsorption by Penicillium sp isolated from kefir. At pH 4.0 this activity did not suffer strong inhibition. Contrary to what was expected there was an increase in biomass when grown in liquid medium which suggests the formation of storage structures of the inorganic contaminant around the cell membrane. These results 
suggest that kefir contains in its composition microorganisms with potential to protect people who consume it from harmful damages caused by inorganic contaminants

\section{Acknowledgements}

Authors would like to thank Coordenação de Aperfeiçoamento de Pessoal de Nível Superior (CAPES) for financial support and EDITAL N N $^{\circ} 15 / 2015$ PROPESPG/UNIFAP - Programa de Auxílio ao Pesquisador. AFO would like to Pos-doctoral scholarship (PNPD/CAPES in PPG/MDR).

\section{References}

ABU-BRAKA, AZ; ZAKI, MS; ABBAS, HH; ISMAIL, NEDA.; KHALIL, R.; TANEKHY, M.; SAAD, T. Filed studies on some probiotics to minimize hazard effects of prevailing inorganic contaminants contamination for improving immunity and growth performance of Oreochromis niloticus. Electronic Physician Journal, 2017; 9(4):4138-4144.

BABICH H., STOTZKY G. Synergism between nickel and copper in their toxicity of microbes: Mediation by pH. Exotoxicology Environmental Safety, 1983; 7:576-587.

BAGY, M.M.K.; EL-SHAROUNY H.M.M.; EL-SHANAWAN A.A. Effect of pH and Organic Matter on the Toxicity of Heavy Metals to Growth of Some Fungi. Folia Microbiology, 1991; 36(4):367-374.

CHEW, AW; RAHMAN, NN; KADIR, MO; CHEN, CC. Dried and wet Trichoderma sp. Biomass adsorption capacity on $\mathrm{Ni}, \mathrm{Cd}$ and $\mathrm{Cr}$ in contaminated groundwater. In: International Conference on Environmental Science and Technology (IPCBEE); 2012; Chennai, India

EL-GENDY, MM. A. A.; HASSENEIM, NM.; IBRAHIM, HAE.; EL BAKY, DHA. Heavy Metals Biosorption from Aqueous Solution by Endophytic Drechslera hawaiiensis of Morus. Mycobiology, 2017; 45(2):73-83.

EL-GENDY, M. M., HASSANEIN, N. A., IBRAHIM, H. A., ABD EL-BAKY, D. H. Evaluation of some fungal endophytes of plant potentiality as low-cost adsorbents for heavy metals uptake from aqueous solution. Australian Journal of Basic and Applied Sciences. 2011; 5:466-473.

ELSANHOTY, RM; AL-TURKI, IA; RAMADAN, MF. Application of lactic acid bacteria in removing heavy metals and aflatoxin B1 from contaminated water. Water Science Technology, 2016; 74(3):625-638.

IANIS, M; TSEKOVA, K; VASILEVA, S. Copper biosorption by Penicillium cyclopium: equilibrium and modeling study. Biotechnology Biotechnology Equipment, 2006; 20:95-200.

JAHROMI, MF.; LIANG, JB.; EBRAHIMI, R; SOLEIMANI, AF; REZAEIZADEH, A; ABDULLAH, N; SHOKRYAZDAN, P. (2017). Protective potential of Lactobacillus species in lead toxicity model in broiler chickens. Animal, 2017; 11(5):755-761.

LA RIVIÉRE, J.W.M.; KOOIMAN, P.; SCHMIDT, K.; Kefiran, a novel polysaccharide produced in the kefir grain by Lactobacillus brevis. Archiv für Mikrobiologie. 1967; 59(1-3):269-278.

\section{MARTÍNEZ-JUÁREZ, V.M.M.; CÁRDENAS-GONZÁLEZ, J.F.; TORRE-BOUSCOULET, M.E.; ACOSTA-RODRÍGUEZ, I.}

Biosorption of Mercury (II) from Aqueous Solutions onto Fungal Biomass. 2012; http://dx.doi.org/10.1155/2012/156190.

OLIVEIRA, AF; SANTOS, CBR; FERREIRA, AM; BEZERRA, RM; ZAMORA, RM; CRUZ, RAS; AMADO, JRR; CARVALHO, JCT. A viability study for the production of biofilms and in silico predictions of major compounds in kefir. Journal of Computational Theoretical Nanoscience. 2017; 14:1-12. 
OLIVEIRA, AF; FERREIRA, AM; FLORENTINO, AC; FERNANDES, CP; GÓES, MB; BEZERRA, RM; SALCEDO, MC; ZAMORA, RM; CARVALHO, JCT. Study of kefir biofilm associated with hydroethanolic extract of Euterpe oleracea Mart. (açai). African Journal of Microbiology Research. 2017; 39:401-410.

RASPANTI, E; CACCIOLA, SO; GOTOR, C; ROMERO, LC; GARCÍA, I. Implications of ceystein metabolism in the heavy metal response in Trichoderma harzianum and in three Fusarium species. Chemosphere, 2009; 76(1):48-54.

SHENG, Y; YANG, X; LIAN, Y; ZHANG, B; HE, X; XU, W; HUANG, K. Characterization of a cadmium resistance Lactococcus lactis subsp. lactis strain by antioxidant assays and proteome profiles methods. Environmental Toxicology Pharmacology, 2016; 46:286-295.

TANWAR, A; GOSWAMI, SP.; ARORA, SK; MATHUR, SP. Biosorption of Cd (II) and Pb (II) ions from aqueous solutions using Carissa carandus. Res J Pharm Biol Chem Science, 2012, 3:614-624.

TONG, Y; ZHAI, Q; LU, W; TIAN, F; ZHAO, J; ZHANG, H; CHEN, W. New insights in integrated response mechanism of Lactobacillus plantarum under excessive manganese stress. Food Res Int., 2017; 102:323-332.

ZHAI, Q; TIAN, F; ZHAO, J; ZHANG, H; NARBAD, A; CHEN, W. Oral Administration of Probiotics Inhibits Absorption of the Heavy Metal Cadmium by Protecting the Intestinal Barrier. Applied Environmental Microbiology, 2016; 82(14):4429-4440. 